\title{
Severe subcutaneous emphysema and pneumomediastinum secondary to noninvasive ventilation support in status asthmaticus
}

\author{
Lara González-García, Corsino Rey, Alberto Medina, Juan Mayordomo-Colunga
}

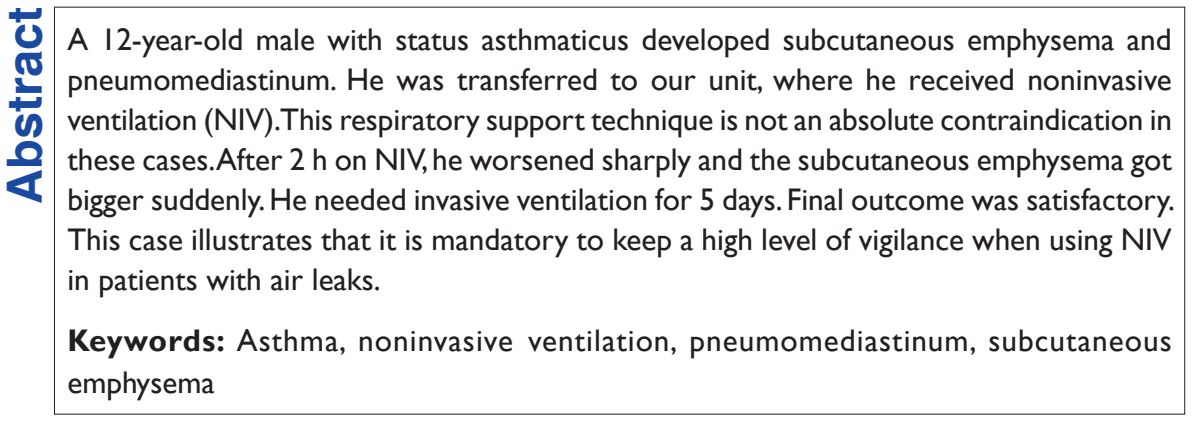

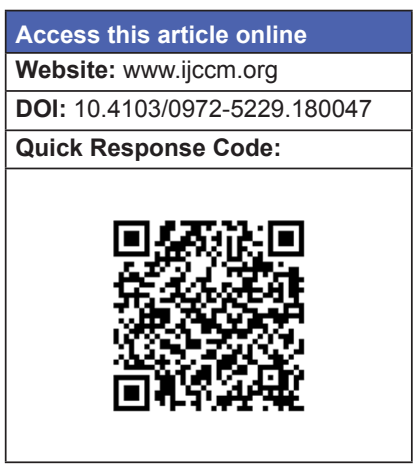

\section{Introduction}

Subcutaneous emphysema is caused by increased intraaveolar or intrabronchiolar pressure with an extrapleural outflow of air. Pneumomediastinum is also due to increased intra-alveolar pressure, which can occur with barotrauma, coughing, or asthma exacerbation. ${ }^{[1]}$ It is more common in children under 7 years. ${ }^{[2,3]}$ During an asthma attack, the incidence is estimated at one in 20,000 patients. ${ }^{[4]}$ There is some controversy about the application of NIV in cases of air leak. We describe the case of a patient with asthma and associated pneumomediastinum and subcutaneous emphysema who showed an abrupt worsening after starting with NIV.

\section{Case Report}

Male patient, 12-year-old, with a history of asthma from the age of 2 years. He was treated with inhaled corticosteroids and long-acting beta agonists, without

\section{From:}

Department of Pediatrics, Pediatric Intensive Care Unit, Hospital Universitario

Central de Asturias, University of Oviedo, Oviedo, Asturias, Spain

\section{Correspondence:}

Dr. Lara González-García, Department of Pediatrics, Pediatric Intensive Care Unit, Hospital Universitario Central de Asturias, University of Oviedo,

Oviedo, Asturias, Spain.

E-mail: laraglezg@gmail.com maintenance therapy during the previous year. He was diagnosed with idiopathic thrombocytopenic purpura at the age of 11. He was admitted to a district hospital with moderate respiratory distress. He was treated with intravenous corticosteroids and nebulized salbutamol and ipratropium bromide. Respiratory distress worsened sharply; he had swelling and crepitus at his neck. Chest X-ray confirmed the presence of subcutaneous emphysema and pneumomediastinum [Figure 1]. He was admitted in the Pediatric Intensive Care Unit (PICU) and connected to NIV. Two hours after NIV initiation his clinical condition worsened abruptly; physical examination revealed neck enlargement of up to two inches thick which compromised airway patency, on auscultation he had a silent chest. Blood gas analysis showed very severe respiratory acidosis $(\mathrm{pH} 7.10$,

This is an open access article distributed under the terms of the Creative Commons Attribution-NonCommercial-ShareAlike 3.0 License, which allows others to remix, tweak, and build upon the work non-commercially, as long as the author is credited and the new creations are licensed under the identical terms.

For reprints contact: reprints@ medknow.com

\footnotetext{
How to cite this article: González García L, Rey C, Medina A, Mayordomo-Colunga J. Severe subcutaneous emphysema and pneumomediastinum secondary to noninvasive ventilation support in status asthmaticus. Indian J Crit Care Med 2016;20:242-4.
} 


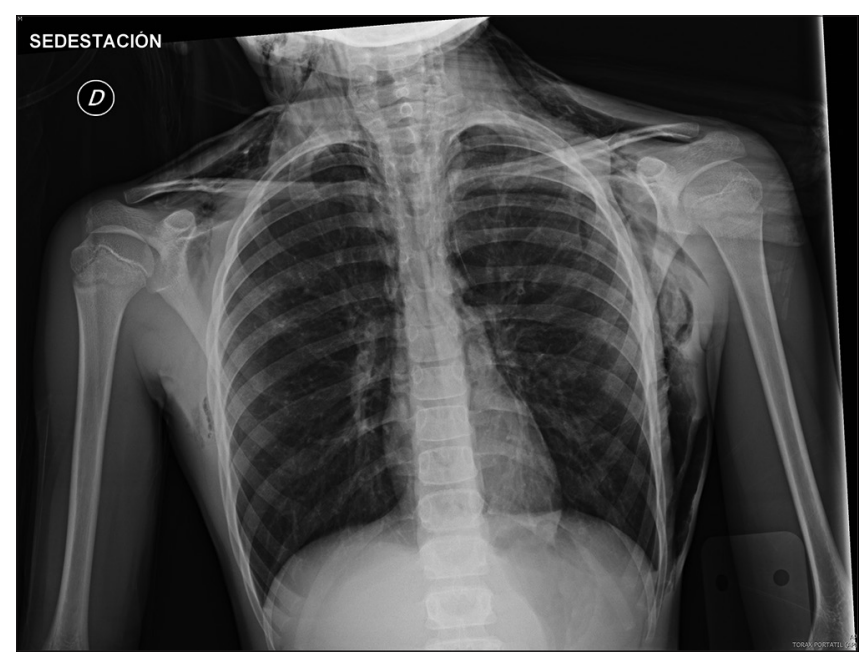

Figure I: Chest $\mathrm{X}$-ray examination showed pneumomediastinum and subcutaneous emphysema

$\left.\mathrm{pCO}_{2} 98.8 \mathrm{mmHg}\right)$. Thorax $\mathrm{X}$-ray and computed tomography (CT) scan showed the presence of subcutaneous emphysema dissecting the muscle compartments of cervical regions, supraclavicular, and costal wall and also showed a pneumomediastinum toward the minor fissure and around the bronchial structures [Figure 2]. The patient required invasive mechanical ventilation (IMV) for 5 days. At the beginning of IMV, he presented air-trapping, showing and intrinsic positive-end expiratory pressure of $5 \mathrm{mmHg}$. Volume-controlled ventilation was used for the first 4 days with a tidal volume of $6 \mathrm{ml} / \mathrm{kg}$. The $5^{\text {th }}$ day ventilation mode was changed to pressure support. Subcutaneous emphysema extended along his chest, abdominal wall and groins. After he was extubated, the outcome was satisfactory, but the signs of subcutaneous emphysema persisted a week after admission, with subsequent resolution.

\section{Discussion}

Subcutaneous emphysema and pneumomediastinum are rare complications of status asthmaticus. If they are present, we have to foresee a sharp deterioration of the patient as it happened in our case. The use of IMV in the asthmatic patient is very uncommon nowadays due to the frequent use of NIV. At present, $<2 \%$ of patients who were admitted to intensive care for asthma exacerbation require IMV. ${ }^{[5]}$ Our patient required IMV because the air leak compromised airway patency. Risk factors for barotrauma in this patient were acute respiratory distress, emphysema, severe asthma exacerbation, young age, and air-trapping. NIV could exacerbate air leak resulting in intense cervical subcutaneous emphysema which almost impeded ventilation (silent chest) probably due to compromised airway. It is mandatory to monitor

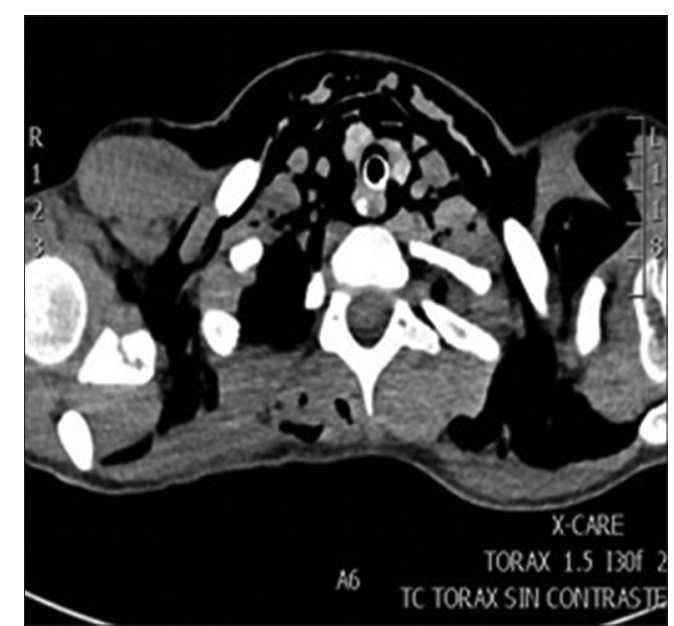

Figure 2: Computed tomography thorax of this patient demonstrating pneumomediastinum and subcutaneous emphysema blowing out of muscles and pneumomediastinum. The chest X-ray of Figure I is before the intubation, and the computed tomography scan is after the intubation

closely patients with air leak (pneumomediastinum in our case) and NIV;[6] especially if it is associated with clinical deterioration or $\mathrm{CO}_{2}$ retention. Literature to date describes an estimated incidence between $5 \%$ and $7 \%$ of pneumothorax or pneumomediastinum using NIV. ${ }^{[7-9]}$ Controversy exists within the consideration of pneumomediastinum as an absolute contraindication in NIV. ${ }^{[10-14]}$ Some authors ${ }^{[10-14]}$ consider NIV as an absolute contraindication whereas others establish that it is a relative contraindication. Therefore, as our case illustrated it is essential to keep a high level of vigilance when using NIV in patients with air leak syndrome. It is necessary to detect changes in mental status or inability to maintain adequate ventilation and oxygenation as soon as possible.

\section{Acknowledgment}

The authors gratefully acknowledge the assistance of the PICU medical and nursing staff of Hospital Universitario Central de Asturias.

\section{Financial support and sponsorship \\ Nil.}

\section{Conflicts of interest}

There are no conflicts of interest.

\section{References}

1. Zhang XY, Zhang WX, Sheng AQ, Zhang HL, Li CC. Diagnosis and prognosis of spontaneous pneumomediastinum in eighteen children. Zhonghua Er Ke Za Zhi 2013;51:849-51.

2. Meireles J, Neves S, Castro A, França M. Spontaneous pneumomediastinum revisited. Respir Med CME 2011;4:181-8.

3. Reed JA, Larson KE, Hsu BS. Spontaneous pneumomediastinum with subcutaneous emphysema: Report of two pediatric cases. S D Med 2013;66:89, 91-3. 
4. Giuliani S, Franklin A, Pierce J, Ford H, Grikscheit TC. Massive subcutaneous emphysema, pneumomediastinum, and pneumopericardium in children. J Pediatr Surg 2010;45:647-9.

5. Hartman ME, Linde-Zwirble WT, Angus DC, Watson RS. Trends in admissions for pediatric status asthmaticus in New Jersey over a 15-year period. Pediatrics 2010;126:e904-11.

6. Carroll CL, Zucker AR. Barotrauma not related to type of positive pressure ventilation during severe asthma exacerbations in children. J Asthma 2008;45:421-4.

7. Fuchs H, Schoss J, Mendler MR, Lindner W, Hopfner R, Schulz A, et al. The cause of acute respiratory failure predicts the outcome of noninvasive ventilation in immunocompromised children. Klin Padiatr 2015;227:322-8.

8. Ruggeri P, Girbino G. Fatal pneumomediastinum associated with use of noninvasive mechanical ventilation. Respirol Case Rep 2014;2:126-8.
9. Nava S, Hill N. Non-invasive ventilation in acute respiratory failure. Lancet 2009;374:250-9.

10. Francisco PA, Pamela SF, Gustavo PT, Carolina CO, Daniel ZA. Asistencia ventilatoria no invasiva en pediatría. Rev Chil Pediatr 2008; 79:580-92.

11. Medina A, Pons-Òdena M, Martinón-Torres F, editores. Noninvasive ventilation in pediatrics, $3^{\text {rd }}$ ed. Madrid: Ergon; 2015.

12. Akingbola OA, Hopkins RL. Pediatric noninvasive positive pressure ventilation. Pediatr Crit Care Med 2001;2:164-9.

13. Caples SM, Gay PC. Noninvasive positive pressure ventilation in the intensive care unit: A concise review. Crit Care Med 2005;33:2651-8.

14. EssouriS, Chevret L, Durand P, Haas V, Fauroux B, Devictor D. Noninvasive positive pressure ventilation: Five years of experience in a pediatric intensive care unit. Pediatr Crit Care Med 2006;7:329-34. 